Available online at : http://journal.unj.ac.id/unj/index.php/gjik

Gladi Jurnal Ilmu Keolahragaan 09 (01) 2018, 56 - 67

Permalink/DOI: https://doi.org/10.21009/GJIK.091.05

\title{
MENINGKATAN KETERAMPILAN LOMPAT JAUH GAYA JONGKOK MELALUI MODIFIKASI ALAT BANTU
}

\author{
Widiastuti $^{1 *}$, Pramudito Hutomo ${ }^{2}$ \\ ${ }^{1}$ Program Studi Pendidikan Jasmani, Fakultas Ilmu Olahraga, Jl. Rawa Mangun Muka, Jakarta \\ Timur, Indonesia 13220 \\ ${ }^{2}$ SMAN 1 Kotagajah Lampung \\ *Corresponding Author. Email: widiastuti@unj.ac.id
}

\begin{abstract}
ABSTRAK
Penelitian ini bertujuan untuk meningkatkan hasil belajar lompat jauh gaya jongkok melalui modifikasi alat . Penelitian ini dilaksanakan di SMAN 1 Kotagajah Lampung. Metode penelitian yang digunakan adalan metode Penelitian Tindakan (Action Research).Teknik pengambilan data dengan pengambilan data kuantitatif dan kualitatif. Hasil penelitian ini adanya peningkatan keterampilan lompat jauh gaya jongkok melalui modifikasi alat. Peningkatan tersebut terlihat dari nilai rata-rata tes siswa, Untuk tes awal $=73.09$, dan kemudian subjek penelitian menunjukan peningkatan pada tes siklus $I=80,84$. Untuk kelulusan subjek penelitian berdasarkan hasil tes awal lompat jauh siswa yang dinyatakan lulus sejumlah 9 siswa (36\%), siklus I siswa yang dinyatakan lulus sejumlah 25 siswa (100\%) Instrumen tes untuk penelitian ini sudah di uji reliabilitaskan, dengan hasil $\mathrm{R}=0,84$. Menurut Suharsimi Arikunto (2006), koefisien $\mathrm{R}=0.84$ dapat dikatakan Reliabilitas Instrumen ini Tinggi.

Kata Kunci : Peningkatan Keterampilan, Atletik, Lompat Jauh Gaya Jongkok, Ekstrakulikuler Atletik, Modifikasi Alat Bantu

ABSTRACT

This study attempts to improve learning outcomes the long jump style squat through modification learning tool .Of research in SMAN 1 Kotagajah Lampung .Research methodology used is research methodology the act of (action research) . technic the data such quantitative data and qualitative .This research result of the study results the long jump style squat through a learning modification .Increased is evident from the test rata-rata students, to test $=73.09$ early, and then students tests showed a rise in cycle $\mathrm{i}=80,84$.To learn students graduation the results of a pretest long jump students who passed a number of 9 students ( $36 \%$ ), cycles i students who passed a number of 25 students ( $100 \%$ ) instrument tests for research has been tested reliability, with the $\mathrm{r}=$ 0,84.According to Suharsimi Arikunto ( 2006 ), the $r=0.84$ can be said this instrument high reliability.
\end{abstract}

Keywords: Increased Study Results , Athletic , the Long Jump Stride Style, Students , Modification Learning Tools. 


\section{PENDAHULUAN}

\begin{abstract}
Proses kegiatan latihan merupakan suatu aktivitas yang bertujuan mengarahkan anggota esktrakulikuler atletik pada perubahan tingkah laku yang diinginkan. Pengertian ini kelihatan cukup sederhana, akan tetapi bila ditelaah lebih mendasar maka akan terlihat lebih rumit dan begitu kompleksnya proses yang dituntut dalam pengelolaan pelajaran itu sendiri, sejalan dengan itu guru pendidikan jasmani dan pelatih haruslah lebih peka dan teliti akan kebutuhan anggota esktrakulikuler atletik yang diajar.
\end{abstract}

Pengamatan yang dilakukan peneliti terletak di SMAN 1 Kotagajah, diperoleh bahwa latihan atletik dengan materi lompat jauh masih terlihat kurang memuaskan. Ini disebabkan kurangnya keterampilan anggota esktrakulikuler atletik dalam melakukan teknik yang cenderung belum baik dan benar sehingga gerakan yang dihasilkan tidak efektif dan efisien. Permasalahan yang dijumpai peneliti adalah guru penjas/pelatih yang mengajar dan melatih di sekolah tersebut tidak menggunakan alat dalam mengajarkan nomor lompat jauh. Alat yang digunakan adalah alat bak pasir lompat jauh saja, sehingga anggota esktrakulikuler atletik setelah mendapatkan arahan dari guru penjas, mereka langsung mempraktikan gerakan tersebut. Secara pemahaman awal anggota esktrakulikuler atletik tersebut sudah mengerti yaitu gerakan diawali dengan berlari, dilanjutkan dengan melakukan tolakan berupa lompatan ke depan, melayang di udara dan diakhiri dengan mendarat. Namun proses dan hasil yang diperoleh menurut peneliti kurang memuaskan dan jauh dari tujuan latihan yang tertuang pada kurikulum khususnya kompetensi dasar.

Modifikasi alat dapat membantu siswa dalam meningkatkan hasil latihan lompat jauh. Alat modifikasi akan memberikan rangsangan anggota esktrakulikuler atletik. Rangsangan ini disesuaikan dengan kondisi materi yang diajarkan. Alat ini akan membantu anggota esktrakulikuler atletik dalam memahami dan mempraktikkan tahapan-tahapan dalam lompat jauh. Alat tersbut dirancang untuk tahapan berlari, lompat, melayang di udara, dan mendarat. Sehingga alat modifikasi akan mempermudah anggota esktrakulikuler atletik dalam melakukan keterampilan lompat jauh tersebut. 
Penelitian ini memiliki kegunaan (a) bagi anggota esktrakulikuler atletik menambah pengetahuan, wawasan, dan kemampuan dalam melakukan keterampilan lompat jauh (b) bagi guru dan pelatih berguna menambah masukan dan pengetahuan untuk variasi dalam modifikasi alat untuk diberikan dalam materi latihan, (c) Bagi peneliti beruguna menambah pengetahuan dalam upaya peningkatan keterampilan anggota esktrakulikuler atletik lompat (d) untuk sekolah berguna menambah perbendaharaan dan tambahan dalam program sekolah untuk pengadaan alat-alat agar memudahkan anggota esktrakulikuler atletik dalam latihan.

\section{KETERAMPILAN LOMPAT JAUH GAYA JONGKOK}

Lompat Jauh adalah suatu bentuk gerakan melompat yang diawali dengan gerakan horizontal dan diubah ke gerakan vertikal dengan jalan melakukan tolakan pada satu kaki yang terkuat untuk memperoleh jarak yang sejauh-jauhnya. Tujuan dari lompat jauh adalah melompat sejauh-jauhnya dengan memindahkan seluruh tubuh dari titik tertentu ke titik lainnya (Wiarto, 2013). Untuk melakukan keterampilan lompat jauh dibutuhkan koordinasi yang baik. Koordinasi adalah kemampuan untuk melakukan gerakan dengan berbagai tingkat kesukaran dengan cepat dan efisien dan penuh ketepatan. Latihan kordinasi dapat dikembangkan pada usia dini antara umur $8-13$ tahun karena di usia ini anak mempunyai karakteristik, yaitu memiliki kecepatan belajar yang luar biasa (James dan Wahyuningtyas, 2012).

Pelatih dan atlet menganggap bahwa atlet lari yang paling cepat adalah calon terbaik untuk lompat jauh, tetapi sebenarnya nomor ini tidak sesederhana itu. Memerlukan waktu dan latihan berjam jam bagi para atlet untuk menguasai tahapan lompat jauh, mereka harus menyempurnakan lari awalan yang efektif, posisi tubuh yang tepat selama bertolakm melayang, dan mendarat (Guthire, 2008).

Gaya jongkok atau sering disebut juga dengan Sail Technique memiliki fase yang sama dengan gaya - gaya lompat jauh yang lain, hanya yang membedakan adalah saat fase take off, melayang di udara, dan mendaratnya. Pada saat posisi menolak/take off tungkai bebas dipertahankan. Badan berada pada keadaan 
tegak ke atas dan vertikal. Kemudian tungkai tolakan mengikuti selama waktu melayang. Tungkai tumpuan dibengkokan dan diatrik ke depan dank e atas mendekati akhir gerak melayang. Baik tungkai bebas maupun tungkai tumpu diluruskan ke depan untuk mendarat. Gerakan lengan sejajar di atas saat melayang di udara, kemudian diayunkan ke depan belakang agar tercipta dorongan ke depan. Kemudian gerakan diakhiri dengan mendarat dalam keadaan jongkok (Guthire, 2008).

Ditinjau dari aspek biomekanika, nomor lompat atletik dapat ditinjau dari tiga parameter : (a) kecepatan tolakan (velocity at take off), (b) sudut tolakan (angle o take off), (c) ketinggian pusat berat saat tolakan (height of the centre of mass at take off). Dari ketiga aspek yang ada, terdapat dua aspek yang sangat penting yaitu kecepatan tolakan lompatan dan sudut tolakan lompatan (Guthire, 2008). Tinggi titik pusat massa ditentukan oleh tinggi badan altet meskipun dipengaruhi oleh posisi pada saat bertumpu. Kecepatan bertolak dan sudut tolakan adalah hasil dari gerakan sebelum dan selama bertolak. Sehingga tolakan ini sangat penting dalam semua nomor lompat (Sidik, 2010).
Struktur gerakan dalam even lompat dapat dibagi menjadi empat fase yaitu : (a) Awalan (Approach), (b) Lompat/ tolakan (Take off), (c) Melayang (Flight), (d) Mendarat (Landing). Birch and Breivik (2007) mendefinisikan keterampilan sebagai

"Skills are obviously at the heart core of sport. Without acquiring and displaying the relevant sport-specific skills one cannot take part in sport contests. Since skills are by definition centrally important in sports, one could have imagined a rich sport philosophic literature on sporting skills”.

Berdasarkan penjelasan di atas, maka dijelaskan bahwa keterampilan adalah sebuah inti dalam olahraga, tanpa menguasai keterampilan maka tidak akan dapat menguasai konten dalam berolahraga. Keterampilan ini memiliki tujuan yang spesifik dan menunjukan sebuah indikator kualitas penampilan.

\section{Modifikasi Alat Bantu}

Peralatan adalah bagian dari sarana. Sarana adalah terjemahan dari facilities yaitu sesuatu yang dapat digunakan dan dimanfaatkan dalam pelaksanaan kegiatan olahraga atau 
pendidikan jasmani. Sarana olahraga yaitu peralatan dan perlengkapan (Samsudin, 2014). Peralatan dapat membantu dalam terjadinya proses belajar dan mengajar pendidikan jasmani di sekolah. Peralatan akan menunjang dan membantu guru dalam proses pembelajaran dan juga meningkatkan minat subjek penelitian dalam menjalani pembelajaran tersebut. Peralatan dapat dibuat sendiri ataupun peralatan yang sudah baku. Oleh karena itu, untuk mengurangi permasalahan dalam minimnya peralatan olahraga yang ada di sekolah, guru harus mampu dalam menemukan atau membuat alat pembelajaran yang baik.

Modifikasi merupakan salah satu upaya yang dapat dilakukan oleh para guru agar proses pembelajaran dapat mencerminkan DAP. Esensi modifikasi adalah menganalisis sekaligus mengembangkan materi pelajaran dengan cara meruntunkannya dalam bentuk aktivitas belajar yang potensial sehingga dapat memperlancar siswa dalam belajarnya. Modifikasi secara umum diartikan sebagai usaha untuk mengubah atau menyesuaikan. Namun secara khusus modifikasi adalah suatu upaya yang dilakukan untuk menciptakan dan menampilkan sesuatu hal yang baru, unik, dan menarik. Modifikasi mengacu pada sebuah penciptaan, penyesuaian dan menampilkan suatu alat/prasarana dan sarana yang baru, unik, dan menarik terhadap suatu proses belajar mengajar dalam pendidikan jasmani (Wiarto, 2015). Sarana yang digunakan dapat dimodifikasi sesuai dengan kondisi sekolah dan karakteristik siswa didik, kondisi sarana yang kurang sebaiknya dimodifikasi sesuai dengan kemampuan atau kondisi yang ada. Peralatan yang dimodifikasi memiliki tujuan untuk membantu proses pembelajaran subjek penelitian. Maka peralatan modifikasi tersebut disesuaikan dengan karakteristik subjek penelitian yang bersangkutan agar peralatan tersebut tepat digunakan untuk membantu proses pembelajaran.

\section{METODE PENELITIAN}

Metode penelitian yang digunakan adalah metode penelitian tindakan (Action Research) dengan desain Kemmis dan McTaggart. Pelaksanaan penelitian melibatkan rekan sejawat sebagai kolaborator dan guru penjaskes sebagai pelaksana tindakan. Hasil akhir dari 
kegiatan penelitian tindakan adalah meningkatkan keterampilan khususnya latihan pendidikan jasmani pada materi lompat jauh dengan menggunakan modifikasi alat bantu pada subjek penelitian SMAN 1 Kotagajah Lampung.

Penelitian ini menggunakan siklus yang mana sklus tersebut mempunyai langkah sistematis yang terdiri dari perencanaan tindakan, pelaksanaan, observasi dan refleksi.

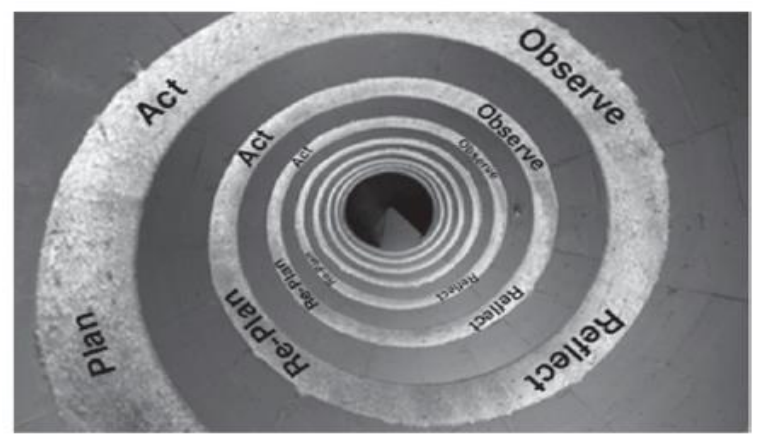

Gambar 1. Model Penelitian Tindakan Stephan Kemmis dan Robin McTaggart

HASIL

PENELITIAN

DAN

\section{PEMBAHASAN}

Penelitian dilaksanakan tiga kali per minggu selama delapan kali pertemuan. Penelitian ini dilakukan di area sekolah SMAN 1 Kotagajah Lampung yaitu pada hari Senin, Rabu, \& Jumat. Subjek penelitian ini adalah anggota ekstrakulikuler atletik SMAN 1 Kotagajah Lampung tahun pelajaran 2016-2017. Pengambilan data tes awal lompat jauh gaya jongkok dilakukan pada tanggal 22 Januari 2017 dan tes akhir siklus I pada tanggal 22 Februari 2017. Hasil Nilai Tes Awal dan Tes Siklus I adalah sebagai Berikut :

\section{Deskripsi Siklus I}

\section{a. Tahap Perencanaan}

Sebelum melaksanakan kegiatan tindakan, peneliti membuat rencana penelitian yang dirancang peneliti. Peneliti bekerjasama dengan guru Penjasorkes untuk menyusun rencana penelitian. Desain penelitian dibuat dan disesuaikan dengan hasil temuan pada observasi peneliti pada data awal proses penelitian pendidikan jasmani dengan materi lompat jauh gaya jongkok pada SMAN 1 Kotagajah lampung.

\section{b. Tahap Pelaksanaan Tindakan}

Dalam tahapan ini peneliti bersama guru pelaksana melaksanakan penelitian dengan menggunakan alat bantu dengan beberapa jenis alat dalam upaya meningkatkan keterampilan lompat jauh 
gaya jongkok. Siklus I ini daharapkan subjek penelitian dapat : 1) mempraktikkan keterampilan lompat jauh gaya jongkok dengan teknik yang benar, 2) menggunakan alat bantu lompat jauh dengan baik, 3) meningkatkan keterampilan lompat jauh gaya jongkok. Penelitian dilakukan pada hari Senin, Rabu, dan Jumat Februari 2017 dan pertemuannya dilakukan pada $07.00-$ 08.30 dan 14.30 - 15.30 yang terdiri dari kegiatan awal, kegiatan inti, dan kegiatan penutup.

\section{a) Kegiatan Awal}

Pada kegiatan awal, peneliti melakukan apersepsi pada subjek penelitian. Mula-mula peneliti mengintruksikan subjek penelitian untuk berbaris 4 baris dan melakukan doa. Peneliti melakukan absensi kepada subjek penelitian yang tidak hadir. Setelah itu peneliti melakukan tanya jawab seputaran tentang materi lompat jauh gaya jongkok untuk mengetahui pengetahuan awal subjek penelitian. Peneliti menjelaskan tentang materi yang akan diajarkan mengenai lompat jauh gaya jongkok serta tujuan yang dicapai setelah mengikuti materi penelitian bersama peneliti. Langkah selanjutnya adalah peneliti mengintruksikan subjek penelitian untuk melakukan pemanasan statis dan dinamis yang dipimpin oleh ketua kelompok. Peregangan meliputi anggota tubuh bagian kepala, lengan, tangan, badan, pinggang, lutut, tungkai, dan kaki.

b) Kegiatan Inti

Pada kegiatan inti ini peneliti memberikan bentuk-bentuk model penelitian menggunakan alat bantu. Penelitian ini didasari oleh tahapan-tahapan yang ada pada lompat jauh yaitu awalan, tolakan, melayang di udara, dan mendarat. Alat-alat yang digunakan juga menyesuaikan dengan fase-fase yang ada dalam lompat jauh tersebut.

Pada tahap awalan, peneliti menggunakan alat bantu cones yang dimodifikasi dengan potongan bambu. Cones tersebut setelah didesain bersama dengan bambu seperti terlihat mini hurdle. Subjek penelitian menggunakan alat ini dengan cara berlari melewati urutan Cones tersebut yang berjarak $40 \mathrm{~cm}$.

Gerakan yang dilakukan adalah berlari tanpa mengurangi kecepatan, dengan gerakan pandangan ke depan, lengan atas dan bawah ditekuk kemudian di ayun diikuti dengan posisi badan yang 
tegak dan posisi tungkai kaki lurus dan lutut tunggi rata-rata air. Subjek penelitian melakukan gerakan tersebut berulang-ulang secara bergantian. Subjek penelitian akan melakukan gerakan tersebut setelah rekannya selesai melakukan gilirannya. Pada pertemuan berikutnya alat yang digunakan adalah cones dan marker. Cones dan marker itu disusun secara memanjang. Susunan pertama adalah marker berjumlah lima buah dan susunan berikutnya adalah cones yang berjumlah lima buah. Awalan yang dilakukan prinsipnya sama seperti pertemuan sebelumnya. Subjek penelitian melakukan gerakan berlari melewati alatalat tersebut.

Pada tahap tolakan atau take off peneliti menggunakan alat bantu modifikasi mini hurdle dengan pipa, box jump, cones and pole. Penggunaan mini hurdle digunakan dengan cara alat tersebut disusun memanjang sebanyak tiga buah dengan masing-masing jarak antar hurdle sepanjang sepuluh meter. Subjek penelitian berlari dan kemudian melompat hurdlehurdle tersebut dengan tolakan kaki yang terkuat secara terus menerus.

Alat berikutnya yang digunakan untuk memberikan latihan tolakan adalah box jump. Box jump ini terbuat dari kayu dengan memiliki karakteristik kemiringan. Subjek penelitian melakukan gerakan take off dengan menggunakan kaki yang terkuat dengan tolakan pada box jump tersebut. Alat ini berfungsi untuk membiasakan kaki aktif dalam melakukan gerakan take off tersebut. Alat terakhir yang digunakan adalah cones and pole. Alat ini memiliki karaktersitik ketinggian pole yang dapat diubah. Subjek penelitian menggunakan alat ini dengan cara diawali dengan gerakan berlari kemudian menolak jangan sampai terkena pole tersebut dan mendarat di matras. Setelah pengulangan ke tiga, maka ketinggian pole akan ditambah setinggi lima sentimeter.

Pada tahap melayang di udara, peneliti menggunakan alat modifikasi bola gantung. Alat ini dipasang pada bak pasir lompat jauh dengan jarak 2,5 meter dari papan tolakan. subjek penelitian menggunakan alat ini dengan cara diawali dengan gerakan berlari kemudian melakukan gerakan take off di box jump dan dilanjutkan dengan gerakan mengayunkan lengan di atas berusaha untuk mengenai bola yang digantung tersebut. Untuk lakilaki ketinggian bola mencapai 3 meter, 
untuk perempuan ketinggian bola 2 - 2,5 meter. Setelah subjek penelitian menggunakan box jump, kemudian box jump dihilangkan dan dilanjutkan mengulangi gerakan yang sama tanpa menggunakan box jump. Ini bertujuan untuk menambah tingkat kesulitan latihan subjek penelitian dalam belajar tentang melayang di udara.

Pada tahap mendarat, diguakan alat bantu berupa box jump dengan ketinggian 50 sentimeter. Cara penggunaan alat ini yaitu subjek penelitian berdiri di box jump tersebut lalu melakukan gerakan melompat ke depan dilanjutkan dengan mendarat dengan stabil. Awal latihan ini dilakukan di pendaratan pada matras, setelah dirasa cukup maka pendaratan dilakukan di media pasir. alat ini berfungsi untuk membiasakan subjek penelitian pada gerakan mendarat dengan gerakan yang baik dan benar.

\section{c) Kegiatan Akhir/Penutup}

Peneliti mengumpulkan subjek penelitian dan memberikan arahan untuk melakukan gerakan pendinginan dengan jogging santai 2 lap dan diakhiri dengen gerakan stretching yang dipimpin oleh ketua kelompok. Dilanjutkan memberikan kesempatan kepada subjek penelitian untuk melakukan tanya jawab kepada peneliti. Ini berfungsi untuk memberikan timbal balik kepada subjek penelitian tentang materi yang telah diajarkan. Setelah dirasa cukup maka peneliti memberikan penguatan/reinforcement kepada subjek penelitian tentang poin-poin penting penelitian lompat jauh agar subjek penelitian memiliki peningkatan presatasi belajar yang baik.

\section{c. Tes dan Observasi Siklus I}

Berdasarkan hasil obervasi terhadap implementasi tindakan pada siklus pertama, selama kegiatan penelitian berlangsung, peneliti dan kolaborator secara bersamasama mengamati subjek penelitian dalam proses penelitian. Tindakan-tindakan yang diberikan oleh peneliti, diobservasi oleh kolaborator. Setelah itu diperlukan sebuah tes untuk mengetahui sejauh mana keterampilan lompat jauh yang telah didapat subjek penelitian melalui modifikasi alat yang digunakan oleh peneliti.

\section{d. Hasil Tes dan Observasi Siklus I}

Berikut adalah data tes yang dilakukan oleh subjek penelitian setelah menjalani perlakuan tindakan sebanyak 
delapan kali pertemuan yang didasari oleh tahapan penilaian dalam melakukan lompat jauh yaitu awalan, tolakan, melayang di udara dan mendarat.

Tabel 1. Hasil Perbandingan Nilai Tes Awal dan Siklus I

\begin{tabular}{|c|c|c|c|c|c|c|}
\hline \multirow{2}{*}{ No } & \multirow{2}{*}{ Ketuntasan } & \multirow{2}{*}{$\begin{array}{c}\text { Standar } \\
\text { Nilai }\end{array}$} & \multicolumn{2}{|c|}{ Tes Awal } & \multicolumn{2}{|c|}{ SiklusI } \\
\hline & & & $\mathrm{F}$ & $\%$ & $\mathrm{~F}$ & $\%$ \\
\hline 1 & Tuntas & 75 & $\begin{array}{c}9 \\
\text { orang }\end{array}$ & $36 \%$ & $\begin{array}{c}23 \\
\text { orang }\end{array}$ & $92 \%$ \\
\hline 2 & $\begin{array}{c}\text { Tidak } \\
\text { Tuntas }\end{array}$ & 75 & $\begin{array}{c}16 \\
\text { orang }\end{array}$ & $64 \%$ & $\begin{array}{c}2 \\
\text { orang }\end{array}$ & $8 \%$ \\
\hline
\end{tabular}

Berdasarkan tabel di atas, maka dapat disimpulkan bahwa terdapat peningkatan subjek penelitian yang mengalami ketuntasan. Pada tes awal terdapat peningkatan sebanyak 14 (56\%) orang yang tuntas, sedangkan terjadi penurunan data subjek penelitian yang tidak tuntas yang berawal dari 16 orang menjadi $0(0 \%)$ orang.

Berdasarkan data catatan lapangan dan data hasil tes siklus I di atas, maka penelitian tindakan tidak dilanjutkan pada tahap siklus selanjutnya. Ini dikarenakan subjek penelitian telah menunjukan peningkatan keterampilan yang baik dan terdapat peningkatan nilai keterampilan di atas kriteria ketuntasan minimal.

\section{KESIMPULAN}

Latihan dengan menggunakan modifikasi alat bantu pada latihan lompat jauh gaya jongkok pada subjek penelitian dapat meningkatkan keterampilan yang signifikan. Persentase ketuntasan keterampilan lompat jauh gaya jongkok pada tes awal yaitu 36\% dan untuk tes siklus I yaitu $100 \%$.

Penggunaan alat bantu latihan ternyata efektif dalam proses latihan lompat jauh gaya jongkok. Alat-alat bantu latihan ini dapat meningkatkan semangat latihan subjek penelitian sehingga mereka memiliki minat dan semangat latihan yang baik.

\section{DAFTAR PUSTAKA}

Arifin, Zainal. Evaluasi Pembelajaran. Bandung : PT Remaja Rosdakarya, 2011

Bahagia, Yoyo. Pengembangan Media Pembelajaran Penjas. Jakarta : Depdiknas Dirjen Pendidikan Dasar dan Menengah 
Birch dan Breivik, Motor Learning and Control (England : Routledge, 2007)

Buku Pedoman Penulisan Tesis dan Desertasi. Jakarta: PPs UNJ, 2012

Costello, Patrick J.M. Action Research. London : Continuum, 2007

Davydd J. Greenwood dan Morten Levin, Introduction to Action Research (London : Sage Publications, 2007)

Don Gordon, Coaching Science (USA : Learning Matters, 2009)

Edward, Derse at al. Track and Field Coaching Manual. USA : LA84, 2008

Freeman H, William, Physiical Education and Sport (Boston : Ally and Bacon, 2005)

Fry, Heather, Steve Katteridge, dan Stepahine Marshall. A Handbook for Teaching and Learning in Higher Education : Second Edition. United States and London : Kogan Page, 2003

Guthrie, Mark. Sukses Melatih Atletik. USA : Human Kinetics, 2008

Huddlestone, Prue dan Lorna Unwin. Teaching and Learning in Further Education : Third Edition. USA : Taylor and Francis, 2007

Kemmis, Stephan, Robin McTaggart, dan Rhonda Nixon. The Action Research Planner : Doing Critical
Participatory Action Research. Singapore : Springer, 2014

Koshy, Valsa. Action Research for Improving Practice. London : Paul Chapman Publishing, 2005

Lisa A. Bridgetss dan Nicholas P. Linthorne, Changes in long jump take-off technique with increasing run-up speed (Sydney : University of Sydney, 2005)

Luzzatto, Edda. Collaborative Learning : Methodology, types of interactions and technique. New York : Noca Science Publisher, 2010

Mc. Ginnis, Peter, Biomechanics of Sport and Exercise (USA : Human Kinetics, 2005)

Mortensen and Cooper, Track and Field For Coach and Athlete (NJ: Englewood Cliffs, 2009)

Mertler, Craig A. Penelitian Tindakan Kelas : Meningkatkan Sekolah dan Memberdayakan Pendidik. Jakarta : PT Indeks, 2014

Nicholl, Gill. Developing Teaching and Learning in Higher Education .New York : Taylor and Francis, 2002

Purwanto, Ngalim. Prinsip - Prinsip dan Teknik Evaluasi Pengajaran . Bandung : PT Remaja Rosdakarya, 2013

Putra, Nusa. Penelitian Tindakan. Bandung : PT Remaja Rosdakarya, 2014 
Richard A. Magil, Motor Learning and Control : Concept and Application (New York : Mc. Graw Hill, 2011

Rosdiani, Dini. Model Pembelajaran Langsung dalam Pendidikan Jasmani dan Kesehatan. Bandung : Alfabeta, 2012

Samsudin, Media Pembelajaran Pendidikan Jasmani (Jakarta : Litera, 2014)

Sidarto, Yusuf. Pemanfaatan Media Pembelajaran untuk Meningkatkan Keterampilan Lompat Jauh Gaya Jongkok. Tesis. Jakarta : UNJ, 2013

Sidik, Dikdik Zafar. Mengajar dan Melatih Atletik. Bandung : Rosda, 2010

Siregar, Eveline. Teori Belajar dan Pembelajaran. Bogor : Ghalia Indonesia, 2011

Sudjana, Nana. Penilaian Hasil Proses Belajar Mengajar. Bandung : PT Remaja Rosdakarya, 2009

Tangkudung, James, dan Wahyuningtyas Puspitorini. Kepelatihan Olahraga "Pembinaan Prestasi Olahraga". Jakarta : Cerdas Jaya, 2012

Thompshon, Peter. Run, Jump, Throw, The Official IAAF Guide to Teaching Athletics. IAAF : Warners Midlands plc, 2009

Trisna Rahayu, Ega, Strategi Pembelajaran Pendidikan Jasmani ( Bandung : Alfabeta, 2013)

U. Jonath, E.Haag, R.Krempel, Atletik (Bandung : PT Rosda Jayaputra, 2008)
Wirhed, Rolf, Athletic Ability \& the Anatomy of Motion (USA : Wolfe Medical Publicatons Ltd, 2007)

Wiarto, Giri. Atletik. Yogyakarta : Graha Ilmu, 2013

Wiarto, Giri, Inovasi Pembelajaran dalam Pendidikan Jasmani (Yogayakarta : Laksitas, 2015)

Winkel, W.S. Psikologi Pengajaran. Yogyakarta : Media Abadai, 2004

Yusuf Sidarto, Pemanfaatan Media Pembelajaran untuk Meningkatkan Keterampilan Lompat Jauh Gaya Jongkok (Jakarta, 2013)

Yoyo Bahagia, Pengembangan Alat Pembelajaran Penjas ( Jakarta : Depdiknas Dirjen Pendidikan Dasar dan Menengah)

Yuya Muraki dan Michiyoshi Ae, Mechanical Properties of Take off leg as a Support Mechanism in the Long jump (Japan : University of Tsukuba, 2012) 